\title{
Multifractal pattern and process during a recent period of forest expansion in a temperate mountainous region of China
}

\author{
Yuxin Zhang a ${ }^{\text {, Keming Ma }}{ }^{\text {a,* }}$, Madhur Anand ${ }^{\text {b,c }}$, Bojie Fu ${ }^{\text {a }}$ \\ a State Key Laboratory of Urban and Regional Ecology, Research Center for Eco-Environmental Sciences, Chinese Academy of Sciences, Beijing, 100085, PR China \\ b School of Environmental Sciences, University of Guelph, Guelph, Ontario, Canada N1G 2W1 \\ c Department of Ecology and Evolution, Princeton University, New Jersey, 08540, United States
}

\section{A R T I C L E I N F O}

\section{Article history:}

Received 7 March 2011

Received in revised form 17 August 2011

Accepted 18 August 2011

Available online 1 September 2011

\section{Keywords:}

Forest landscape change

Fractal growth

Multifractal

Rényi spectra

Scaling law

Forest expansion

\begin{abstract}
A B S T R A C T
Understanding the mechanisms that drive spatial pattern change over space and time is a central goal of landscape ecology, but these patterns are often complex. Multifractals, an extension of the concept of fractal geometry, is especially suited to the description of complex pattern. In our paper, we examine the scaling properties of forest spatial pattern over 32 years of forest expansion in a warm temperate deciduous forest near Beijing city using multifractal analysis. An idealized fractal growth model was used to simulate spatial patterns and to link patterns to processes. We show that the despite substantial increases in forest cover, the scaling properties of the spatial pattern of the forest landscape remains similar over time. The variance of Rényi spectra among different years implied that the changes in the forest landscape over time may be a fractal growth process. The fact that these scaling behaviors persist across a heterogeneous landscape suggests that simple rules could exist for some processes of forest expansion, facilitating prediction and further modeling efforts.
\end{abstract}

(c) 2011 Elsevier B.V. All rights reserved.

\section{Introduction}

Understanding landscape spatial pattern change over space and time and finding the underlying governing processes is a central goal of landscape ecology. The ecological importance of this understanding is heightened by the dramatic changes in landscapes that are occurring in response to global ecological changes. Though forest cover has declined in many parts of the world, some regions are exhibiting a "forest transition" in which forest cover has increased over the past few decades, including China (Rudel et al., 2005). There are several processes involved in these observed trends (Nagendra and Southworth, 2010), however very little attempt has been made to quantitatively examining the patterns and processes involved in these dramatic changes in forest cover. In addition, while understanding aggregate indicators such as percent cover are important, other measures may be required to untangle governing spatiotemporal processes.

Ecological patterns and processes and their relationships are dependent on scale (Levin, 1992) and thus analyzing ecological pattern across scales is critical for our understanding of underlying processes (Wiens, 1989). Cross-scale analysis of ecological pattern is a difficult but hot topic in ecology. It has been suggested that finding scaling

\footnotetext{
* Corresponding author. Tel./fax: +861062849104.

E-mail address: mkm@rcees.ac.cn (K. Ma).
}

laws can be a way to unify natural phenomena (Feigenbaum, 1979). To this end, power law scaling is the most commonly and widely used scaling law in ecology (Arrhenius, 1921; Borda-de-Água et al., 2002; Gaston and Blackburn, 2000; Milne, 1991; West and Brown, 2005; White et al., 2008). The power law is usually related to selfsimilar (fractal) structures in nature (Harte et al., 1999; Ostling et al., 2004; Zhang et al., 2006). The distribution of species, populations and communities in forest landscapes have been shown to have power-law related fractal properties (Borda-de-Água et al., 2002; Drake and Weishampel, 2000, 2001; Enquist et al., 2009; Harte et al., 1999; Ostling et al., 2004; Pagnutti et al., 2007; Scheuring and Riedi, 1994; West et al., 2009; Zhang et al., 2006) and thus some hope for generalizability of these patterns still exist.

In addition to intrinsic (biotic) factors, the spatial pattern of forests is determined by many extrinsic (often abiotic) factors, such as topography, soil, and climate (Forman, 1995). These factors are themselves fractally distributed in nature (Caniego et al., 2005; Deidda et al., 1999; Kravchenko et al., 2000; Ma et al., 2001; Martinez et al., 2009; Montero, 2005; Zeleke and Si, 2004). The interactions of abiotic and biotic factors increase complexity (Turner and Romme, 1994), thus no single universal scaling factor describing the scaling of the pattern should be expected, but rather a spectrum of scaling exponents (Scheuring and Riedi, 1994) might be observed. Indeed a well-developed technique, namely multifractal analysis, assumes that no single fractal dimension $(D)$ describes patterns observed in nature (Feder, 1988; Milne, 1991; Scheuring and Riedi, 1994). The 
Rényi spectrum (Rényi, 1970) of multifractal theory is a flexible extension of the power law fractal. Milne (1991) suggested that multifractal analysis is a useful tool for describing landscape pattern. It could help in our understanding of different ecological interactions generating patterns, and could be a good indicator of ecological processes in space and time (Carranza et al., 2007; Scheuring and Riedi, 1994).

Recently several studies have examined the processes generate power-laws in vegetation patch patterns using simple cellular automata type models of growth dynamics (Kéfi et al., 2007; Pagnutti et al., 2007; Scanlon et al., 2007). These models have all pointed to the importance of local interactions for generating observed power-laws in landscape patterns. However, while several of these studies attempt to capture single power-laws, some of them present results suggesting that landscapes can vary in fractal dimension according to environmental conditions. Indeed, fractal patterns can also change in time. In general, linking fractal-based ecological indicators to temporal processes remains a challenge in ecology, as many different processes can generate fractal patterns. One approach is to follow indicators over time and examine correlative trends, but this has obvious logistic limits. Another approach is to construct a dynamical model of the process and correlate output with observed patterns. We use the latter approach to examine forest spatial pattern change over time in a mountainous area of Beijing, China. Our aim is determine whether forest spatial patterns, as measured by multifractal indicators, have changed in time in concert with dramatic increases in forest cover and whether these can be linked to simple rules of forest expansion.

\section{Methods}

\subsection{Data sets}

\subsubsection{Forest spatial data}

We use Landsat data to detect the change in spatial patterns of forest cover over time (1978, 1991, 2002 and 2010) of Beijing, China. The municipality is located at $39^{\circ} 56^{\prime} \mathrm{N}$ and $116^{\circ} 20^{\prime} \mathrm{E}$, covers an area of $16,808 \mathrm{~km}^{2}$. The four periods of Landsat data are all taken for path 123 and row 32. Except the first period (May 6, 1978) for which MSS data is used with a spatial resolution of $80 \mathrm{~m} \times 80 \mathrm{~m}$, TM data are used for other periods (May 6 1991,May 16, 2002 and May 05,
2010) and the spatial resolution is $30 \mathrm{~m} \times 30 \mathrm{~m}$. All data is interpreted in two classes (forest and non-forest) using supervised classification method in Erdas Image 8.5. The total classification accuracy is $85.96 \%$, assessed by Accuracy Assessment modular of the software.

A $28.8 \mathrm{~km} \times 28.8 \mathrm{~km}$ site, nearly $50 \mathrm{~km}$ west of Beijing city, is selected for data analysis (Fig. 1). In this area, the climate is a typical warm temperate continental monsoon climate with average annual precipitation of 500-650 mm (from low elevation to high elevation). The mean annual temperature is $5-10^{\circ} \mathrm{C}$. This area also has high heterogeneity in the landforms. Most of the area is more than $600 \mathrm{~m}$ above sea level. The vegetation of this region is a secondary deciduous broad-leaved forest (Chen, 1997). Oak (Quercus liaotungensis Koidz.), birches (Betula platyphylla Suk., Betula dahurica Pall., Betula chinensis Maxim.), maple ( Acer mono Maxim.), and poplar (Populus davidinna Dode.) are the dominant species in this area.

\subsubsection{Fractal growth model: simulated data}

The fractal growth model can successfully describe the complicated patterns in nature for they capture the simple physical mechanisms underpinning associated phenomena. Several types of models have been developed to simulate different types of fractal growth phenomena. These models include ballistic aggregation, Eden growth, diffusion-limited aggregation and local growth models (please see Vicsek, 1992 for details). Here we only selected diffusion-limited aggregation (DLA) model to simulate the forest growth process. DLA is one of the most important models of fractal growth, the growth rule is remarkably simple (Witten and Sander, 1981). This model has been used to simulate many different biological processes including the evolution of drainage networks (Masek and Turcotte, 1993), tree root growth (Hauhs et al., 1995), and clonal growth (Sintes et al., 2005). The model, simply explained, involves a random diffusion process combined with some limits which lead to aggregation. We use this model because of its simplicity, but also because the processes of diffusion and aggregation are ones that we consider important for forest spread across a heterogeneous landscape.

A Matlab code DLA simulator is used to generate fractal growth patterns (http://leto.net/math/dla.php). We select 60,000 particles on 1920 by 1920 grid as maximum cluster mass to simulate the fractal growth process. Many images (cluster mass 5000, 5100, 5200, 5300, .....60,000) are generated. Multifractal methods are used to analyze these generated

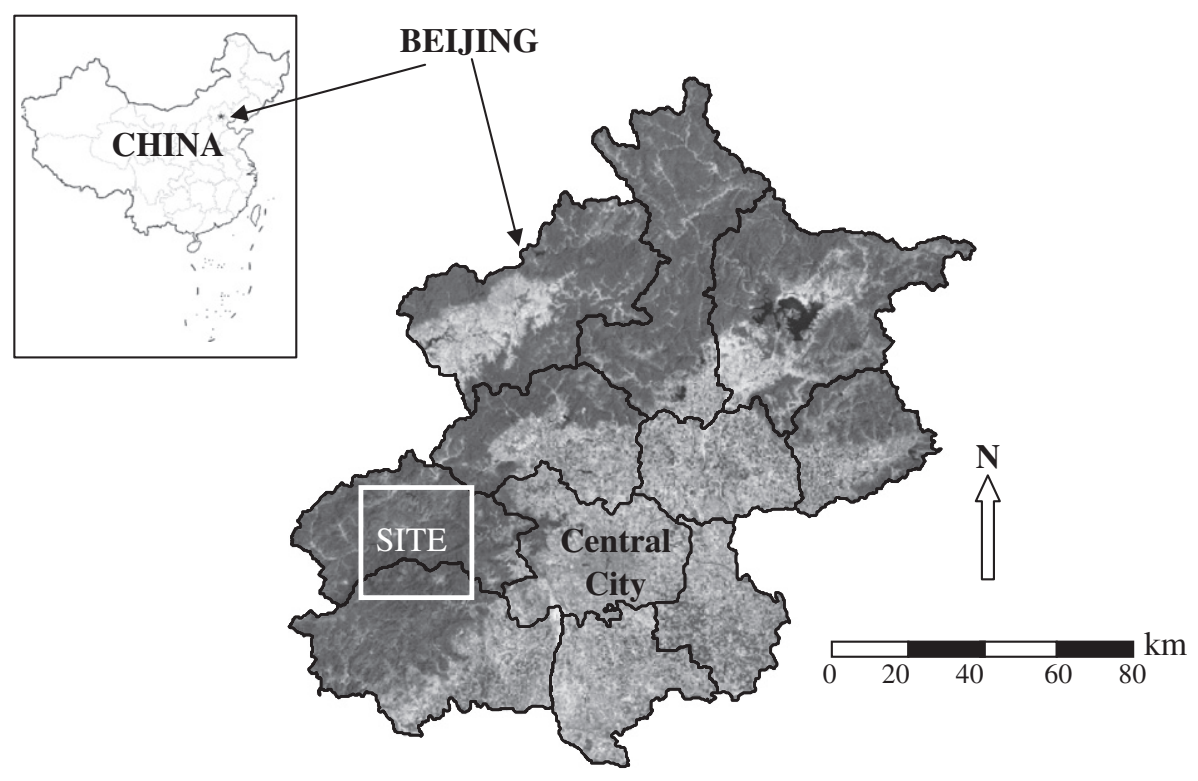

Fig. 1. The location of the forest sites used in our study. 
spatial patterns. In order to compare these with forest distribution data, the DLA generated images are matched with the forest spatial data in the same scale using ArcGIS software.

\subsection{Multifractral analysis}

In landscape ecology, this following scaling law has been used most commonly to calculate the landscape fractal dimension via the box counting method (Milne, 1991, 1992):

$N(\delta) \approx \delta^{D}$

where $N(\delta)$ is the number of boxes (area or cells) occupied; $\delta$ is the size of box; $D$ is the fractal dimension. However, this method represents a special case of spatial pattern analysis, because $N(\delta)$ only examines the presence and absence ( 0 or 1 ) of data, not the proportion within a box. This may not be sufficient to describe the complex patterns of landscapes (Milne, 1992; Ricotta, 2000; Scheuring and Riedi, 1994). The multifractal method used here is a derivation of this method (Everstz and Mandelbrot, 1992).

To implement the 'box-counting' method for multifractal analysis of a distribution supported on an interval $\mathrm{I}=[\mathrm{a}, \mathrm{b}]$, a set of different grids with cells of I with equal size is required, and scaling down is the commonly used method (Harte, 2001). First, a set of different grid with rectangular cells of the size $\delta$ is used to partition study area. Each cell is characterized by a grid size $(\delta)$, and the ratio between forest area of the cell and the forest cover of the site (the relative area of the cell), $\mu_{i}(\delta)$. Nine cell sizes $(\delta)$ are considered in this study, with the total number of cells $N(\delta)$ in the site (Fig. 2). In every site partitioning process, we re-calculate the relative area of both the forest distribution data and the DLA generated data in each cell $u_{i}(\delta)$ with cell size $(\delta)$.
Rényi dimensions are used for data analysis. Rényi dimensions (Hentschel and Procaccia, 1983; Rényi, 1970), $D_{q}$, also called generalized dimensions, are defined as:

$D_{q}=\lim _{\delta \rightarrow 0} \frac{1}{q-1} \frac{\log \left[\sum_{i=1}^{N(\delta)} \mu_{i}(\delta)^{q}\right]}{\log (\delta)} \quad q \neq 1$

$D_{1}=\lim _{\delta \rightarrow 0} \frac{\sum_{i=1}^{N(\delta)} \mu_{i}(\delta) \log \left(\mu_{i}(\delta)\right)}{\log (\delta)} \quad \mathrm{q}=1$

Parameter $q$ acts as a scanning tool scrutinizing smaller versus larger values of the measure $\mu_{i}(\delta)$ along the support (Kravchenko et al., 2000). For $q>>1$, regions with a high degree of concentration are amplified, while regions with a small degree of concentration are magnified for $\mathrm{q}<<-1$ (Montero, 2005). In order to give a solution of $D_{q}$, another formula originating from Eqs. (1) and (2) is introduced:

$I_{q}(\delta)= \begin{cases}\frac{1}{q-1} \log \left[\sum_{i=1}^{N(\delta)} \mu_{i}^{q}(\delta)\right] & q \neq 1 \\ -\sum_{i=1}^{N(\delta)} \mu_{i}(\delta) \log \left[\mu_{i}(\delta)\right] & q=1\end{cases}$

where $I_{q}(\delta)$ called Rényi information.

By changing the size of $\delta$, we can calculate a series $I_{q}(\delta)$, and plot $\log (\delta)$ against $I_{q}(\delta)$. The dimensions $D_{q}$ are estimated by least square fitting of the $\log (\delta)-I_{q}(\delta)$ plot. The absolute value of the slope of the fitting line is $D_{q}$. Coefficients of determination $\mathrm{R}^{2}$ and significance of those fits are then obtained. This process is repeated for $q$ ranging from -10 to 10 in increments of 0.5 . In plotting $q$ versus $D_{q}$, we obtain the Rényi spectra.

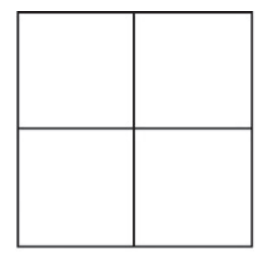

(a) $\delta=14400 \mathrm{~m} \times 14400 \mathrm{~m}$ $N(\delta)=4$

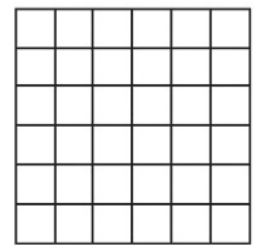

(d) $\delta=4800 \mathrm{~m} \times 4800 \mathrm{~m}$ $N(\delta)=36$

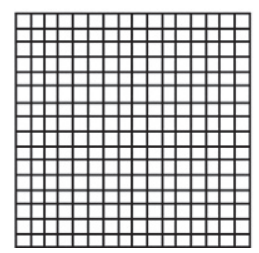

(g) $\delta=1800 \mathrm{~m} \times 1800 \mathrm{~m}$ $N(\delta)=256$

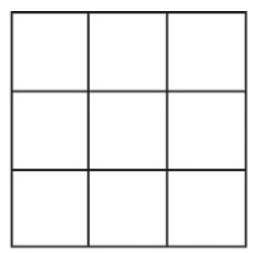

(b) $\delta=9600 \mathrm{~m} \times 7600 \mathrm{~m}$ $N(\delta)=9$

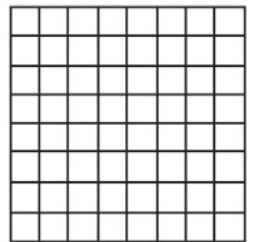

(e) $\delta=3600 \mathrm{~m} \times 3600 \mathrm{~m}$ $N(\delta)=64$

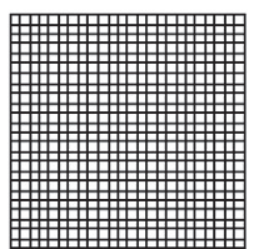

(h) $\delta=1200 \mathrm{~m} \times 1200 \mathrm{~m}$ $N(\delta)=576$

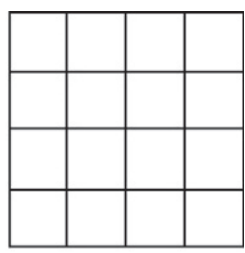

(c) $\delta=7200 \mathrm{~m} \times 7200 \mathrm{~m}$ $N(\delta)=16$

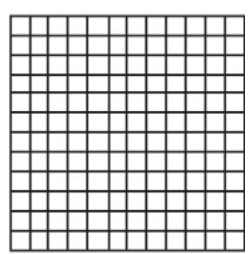

(f) $\delta=2400 \mathrm{~m} \times 2400 \mathrm{~m}$ $N(\delta)=144$

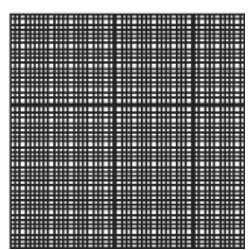

(i) $\delta=600 \mathrm{~m} \times 600 \mathrm{~m}$ $N(\delta)=2304$

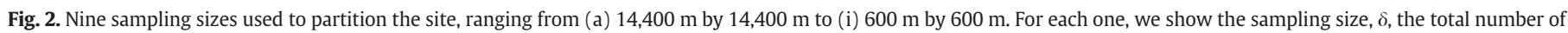
the cells, $N(\delta)$. The size of the site is $28800 \mathrm{~m}$ by $28800 \mathrm{~m}$. 


\section{Results}

The forest appears to change over the past few decades in the region surrounding Beijing, China with a clear trend in forest expansion from 1978 to 2010 (Fig. 3(a)-(d)). The forest coverage rate increases gradually, from $17.16 \%$ in 1978 to $49.36 \%$ in 2010 . Forests are naturally distributed at high elevations in this area (Fig. 3(a)-(d) and (e)). This is partly due to low disturbance of human activity and the favourable environmental conditions (the average annual precipitation is higher at high elevations than at low elevations). Fig. 4 shows the multifractal spectra of the forest spatial pattern in different years; each point of multifractal spectra is statistically significant $(\mathrm{P}<0.0001)$. The best and worst fits for value $D_{q}$ are shown in Fig. 5 (a, b). The $D_{q}$ values in multifractal spectra increase with time from 1978 to 2010 . The left part $(\mathrm{q}<0)$ of the spectra is increasing faster than the right part $(q>0)$ of the spectra over time. This means that (a)

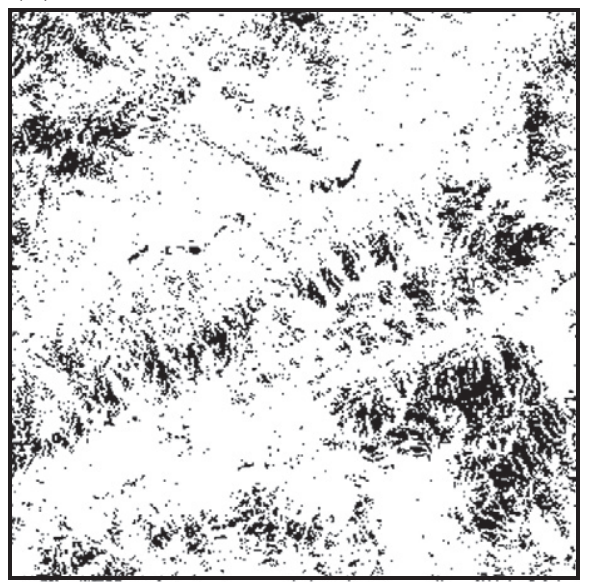

(c)

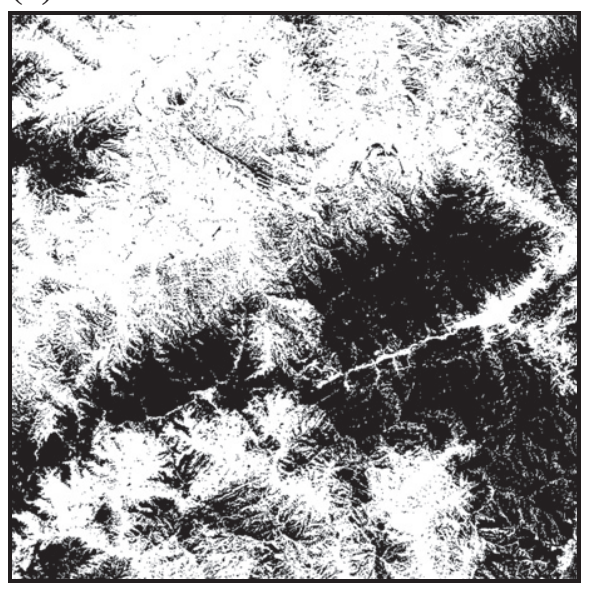

(b)

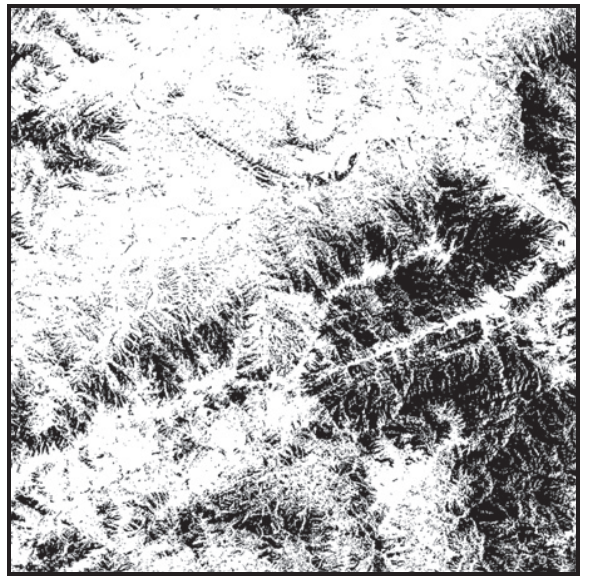

(d)

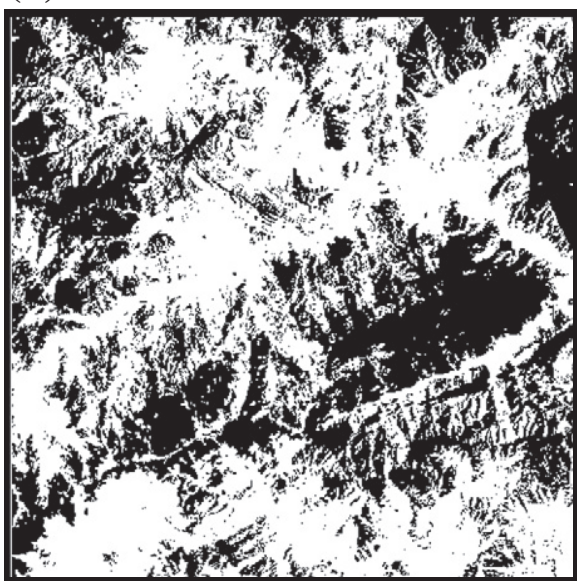

(e)

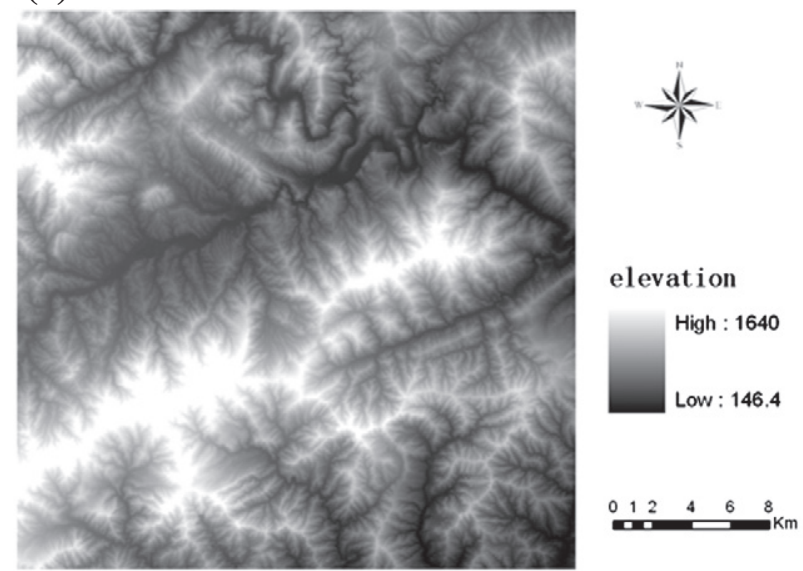

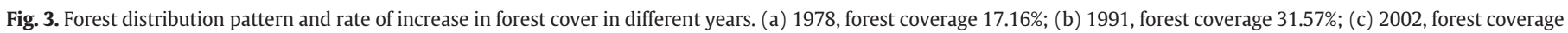
43.16\%; (d) 2010, forest coverage 49.36\%. (e) Landform of the forest data site. The elevation unit of legend is meter (m). 


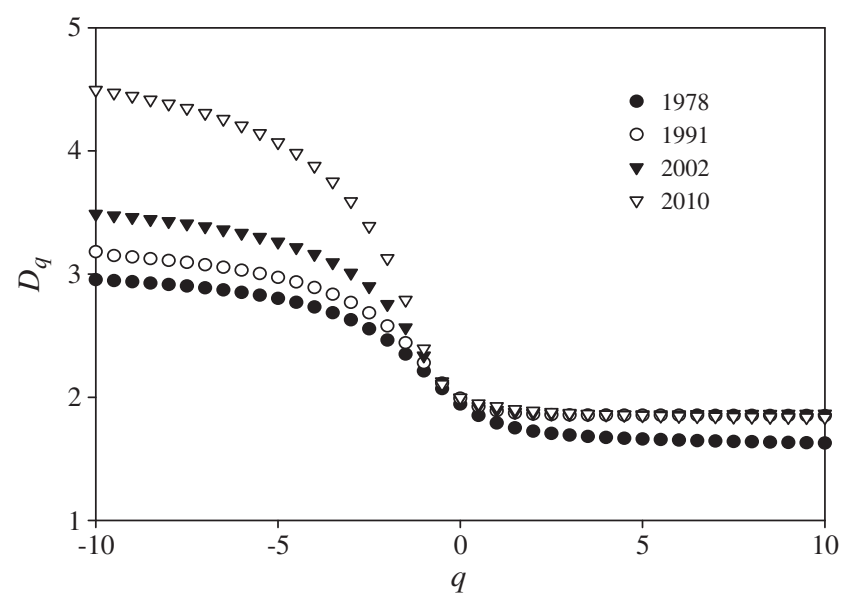

Fig. 4. $D_{q}-q$ curves of forest distribution pattern in different years.

small forest landscape patches are decreasing faster than the increase in large patches. Smaller patches contribute more to the $D_{q}$ value in the left part of the spectra, and large patches contribute more to the right part of the spectra. The difference $\left(D_{q \max }-D_{q \min }\right)$ between maximum value of $D_{q}$ and minimum values of $D_{q}$ are 1.3271(1978), 1.3304 (1991), 1.6278 (2002), and 2.6603(2010) respectively.

The DLA model generated spatial patterns that gradually expand in space at different fractal growth stages which resemble the landscape forest spatial pattern. We selected four images for which the cluster masses (CM) number is 13,$000 ; 25,500 ; 34,000$; and 60,000 respectively (Fig. 6 ) as a demonstration because the multifractal spectra are similar to that of the forest distribution pattern spectra $(\mathrm{q}<0)$ (Figs. $4 ; 7)$. The values of $D_{q}$ in each spectra show an increasing trend with the fractal growth process, and each point of the multifractal spectra is statistically significant $(P \leq 0.0005)$. Fig. 5(c, d) shows the best and worst fits for value $D_{q}$ of the DLA model generated pattern. The left part of the spectra is also increasing faster than the right part. The difference between the maximum value of $D_{q}$ and the minimum value of $D_{q}$ are 1.4365 (CM 13000), 1.5699 (CM 25500), 1.8663 (CM 34000), and 2.2182 (CM60000) respectively.

\section{Discussion}

Forest landscapes have complex patterns and processes in space and time (Bradbury et al., 2000; Gisiger, 2001; Klomp and Green, 1996). The spatial-temporal complexity in nature could be described by many methods, but information theory-based power law scaling seems to be an effective tool in describing such complexity (Loehle and Wein, 1994; Ricotta, 2000; Ricotta and Anand, 2006). We find that the scaling laws for forest spatial patterns hold over time $(1978,1991,2002$, and 2010) in our study site, despite dramatic increases in forest cover. This result is interesting in and of itself because it suggests that the expansion of forests in this region is following a process with some constraints. The processes of expansion need to be studied further. Afforestation (planting) is largely the cause of forest cover expansion in China in recent decades (Song and Zhang, 2010). However, most afforestation sites are located in lowland areas and consist of different types of forests (e.g. pine, larix and cypress are the main planting species). Some planting is also done on higher elevations (those of our sites) and could have contributed somewhat to the expansion observed in the area we studied, thus rendering the process both 'natural' and human-induced. At the landscape scale, forest spatial pattern is the result of an integration of climate, landform, disturbance and biotic factors (Turner and Romme, 1994). Further studies could examine longer time series to determine whether there exists transitions or thresholds in this behavior over time in this region and whether the patterns observed also hold in forests undergoing expansion in other parts of the world.

The similarity between the multifractal spectra change over time of forest distribution patterns and the fractal growth model generated patterns implies that forest expansion over time in this region could follow a fractal growth process. The fact that the scaling properties of forest spatial distribution over time is important, as it implies that a simple model could describe the spatial-temporal complexity of landscape evolution (Bolliger et al., 2003). This then suggests that simple rules could be used to model forest dynamics as has been suggested also in other studies (Colasanti et al., 2007; Pagnutti et al., 2007; Sturtevant et al., 2004). Most of the dominant species are dispersed by wind (i.e. birches, maple, poplar) and this may represent some of the 'random' aspect of DLA in this area, but the precise dispersal patterns of the dominant species would need to be further investigated to confirm this. Furthermore, often in forests, growth
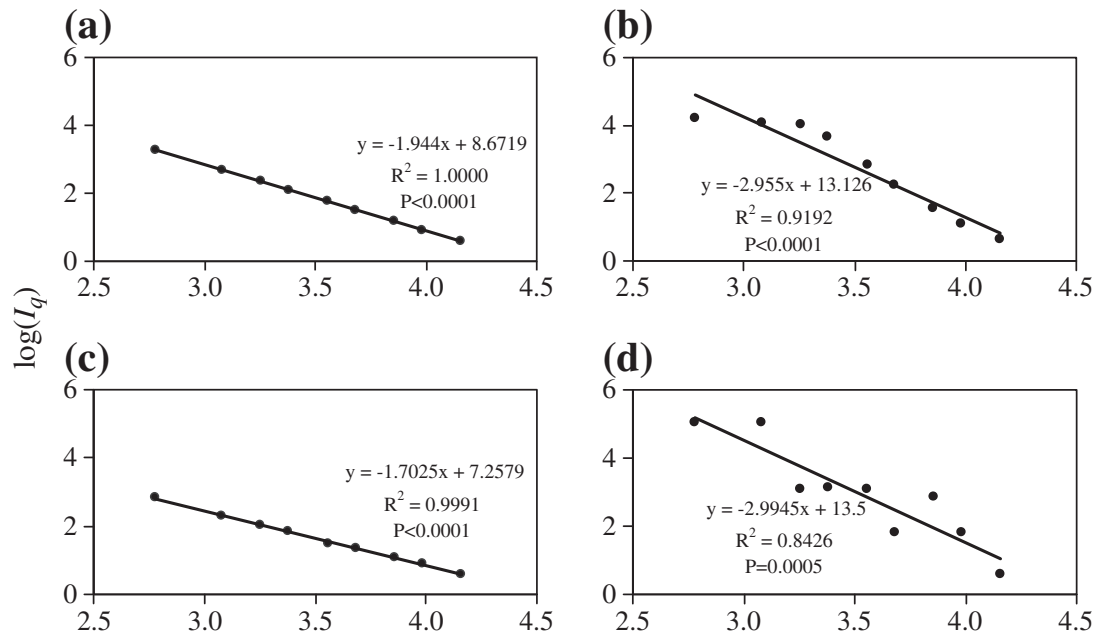

(d)

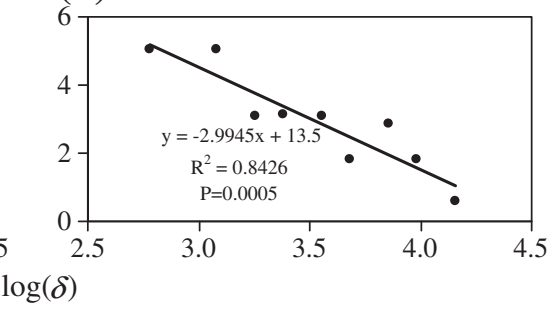

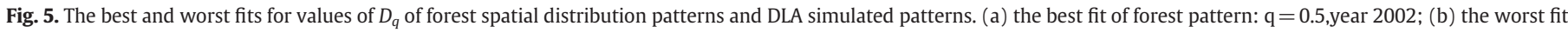

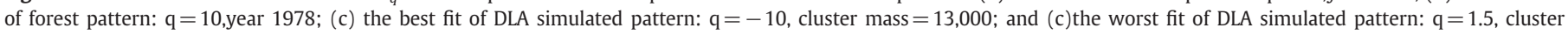
mass $=34,000$. 

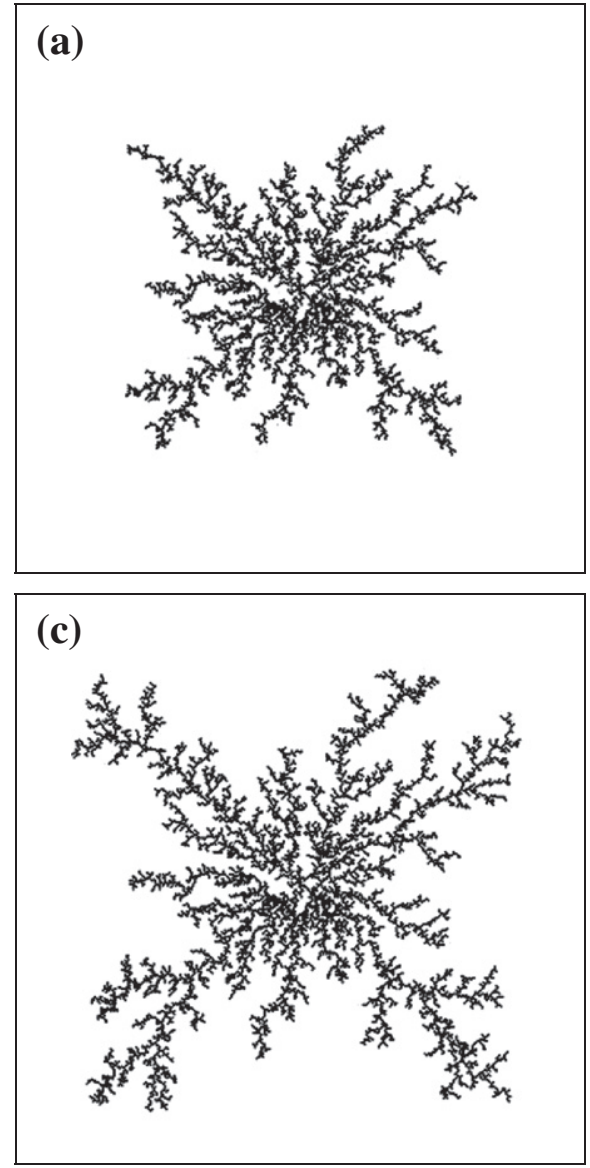

Fig. 6. DLA model generated spatial patterns. (a) Cluster mass $=13,000$ particles; (b) mass $=60,000$ particles

conditions improve where there are established individuals (Padilla and Pugnaire, 2006), leading to the clustering observed in the growth patterns.

While admittedly the DLA may not be the best model for the relatively recent but ongoing forest expansion process in China (and was used here mainly for illustrative purposes), other models should be developed and tested keeping the above ideas in mind. There are also external factors, not explicitly included in the simple DLA that could be taken into account

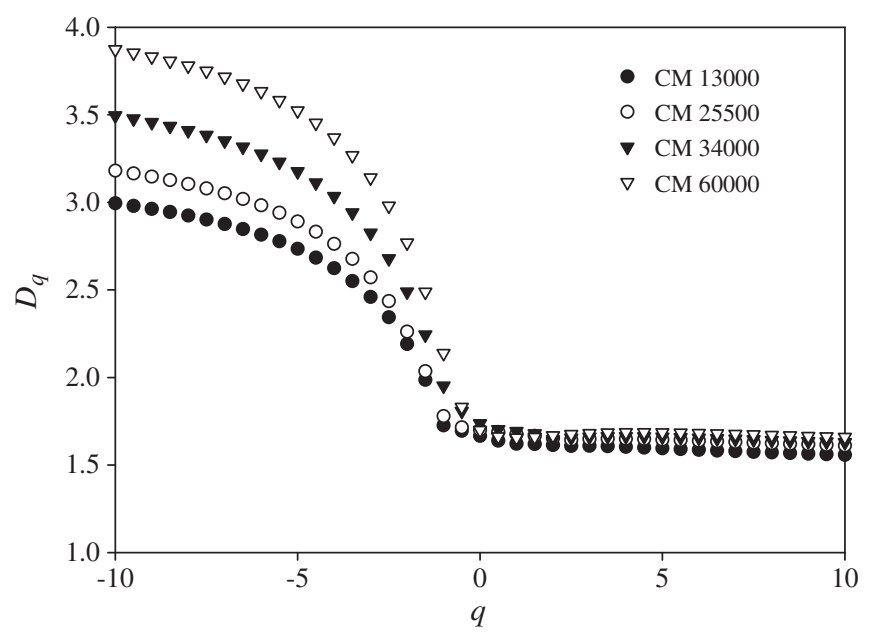

Fig. 7. Dq-q curves of DLA generated patterns. CM: Cluster Mass. (b)

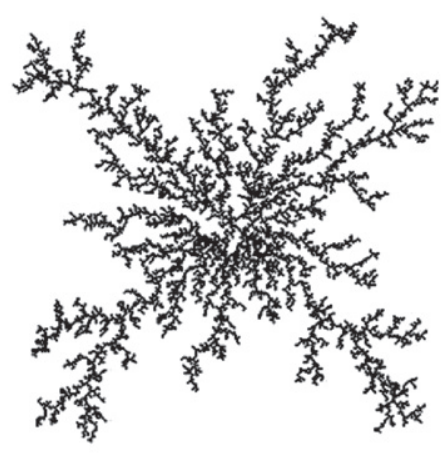

(d)

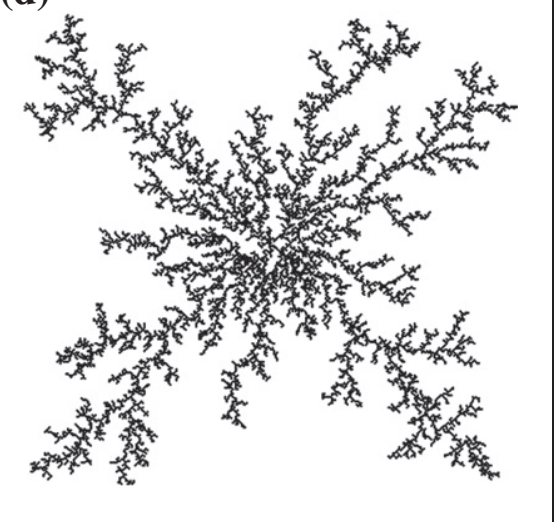

to explain the spatial patterns observed: the establishment of seedlings can be spatially limited because habitat conditions are more favourable at high elevations than at low elevations. This may result in the limited aggregation of individuals establishing at higher elevations first and then expanding gradually (Fig. 3(a)-(d) and (e)). Having said this, the work of Tang (2008) could be relevant to examine implications of changing land-use management (e.g., reforestation programs) as it has shown that occupancy probability in the DLA model can strongly affect spatial structure. Kendal (1992) suggested that the tendency of organisms to form aggregations could be thought of as a special case of diffusionlimited aggregation. Furthermore, Maurer and Taper (2002) have argued that that such simple models should be applicable and that "organisms may be aggregated across several spatial scales by a combination of the need to aggregate to reproduce, the ecological limitations inherent in their fundamental niches, and by the nonrandom distribution of ecological conditions imposed by a heterogeneous environment." Further studies on such problems are suggested, because it could bring us closer to integrating static and dynamic approaches to examining both natural and human-mediated changes in forest systems.

\section{Acknowledgements}

We thank Yan Piao, Bing Xia and Liang Zhou for their help in remote sensed data interpreting. This work is supported by National Key Basic Research Program (2009CB421104), National Natural Science Foundation of China (30870459, 30900185), and State Key Laboratory of Urban and Regional Ecology Grant (SKLURE2008-1-02). This work was also supported by grants from the Natural Science and Engineering Council of Canada and the Canada Research Chairs program to M.A. 


\section{References}

Arrhenius, O., 1921. Species and area. J. Ecol. 9, 95-99.

Bolliger, J., Sprott, J.C., Mladenoff, D.J., 2003. Self-organization and complexity in historical landscape patterns. Oikos 100, 541-553.

Borda-de-Água, L., Hubbell, S.P., McAllister, M., 2002. Species-area curves, diversity indices, and species abundance distributions: A multifractal analysis. Am. Nat. 159, $138-155$.

Bradbury, R.H., Green, D.G., Snoad, N., 2000. Are ecosystems complex systems? In: Bossomaier, T.R.J., Green, D.G. (Eds.), Complex systems. Cambridge University Press, pp. 339-366.

Caniego, F.J., Espejo, R., Martin, M.A., San Jose, F., 2005. Multifractal scaling of soil spatial variability. Ecol. Model. 182, 291-303.

Carranza, M.L., Acosta, A., Ricotta, C., 2007. Analyzing landscape diversity in time: The use of Renyi's generalized entropy function. Ecol. Indic. 7, 505-510.

Chen, L.Z., 1997. The importance of Donglingshan mountain region in warm temperate zone deciduous broad-leafed forests. In: Chen, L.Z. (Ed.), Study on the structure and function of forest ecosystem in warm temperate zone. Chinese Science Press, Beijing, pp. 1-9.

Colasanti, R.L., Hunt, R., Watrud, L., 2007. A simple cellular automaton model for highlevel vegetation dynamics. Ecol. Model. 203, 363-374.

Deidda, R., Benzi, R., Siccardi, F., 1999. Multifractal modeling of anomalous scaling laws in rainfall. Water. Resour. Res. 35, 1853-1867.

Drake, J.B., Weishampel, J.F., 2000. Multifractal analysis of canopy height measures in a longleaf pine savanna. For. Ecol. Manage. 128, 121-127.

Drake, J.B., Weishampel, J.F., 2001. Simulating vertical and horizontal multifractal patterns of a longleaf pine savanna. Ecol. Model. 145, 129-142.

Enquist, B.J., West, G.B., Brown, J.H., 2009. Extensions and evaluations of a general quantitative theory of forest structure and dynamics. PNAS 106 (17), 7046-7051.

Everstz, C.J.G., Mandelbrot, B.B., 1992. Multifractal measures. In: Peitgen, H., Jürgens, H., Saupe, D. (Eds.), Chaos and Fractals. Springer, Berlin, pp. 921-953.

Feder, J., 1988. Fractals. Plenum, New York.

Feigenbaum, M., 1979. The universal metric properties of nonlinear transformations. J. Stat. Phys. 21, 669-706.

Forman, R.T.T., 1995. Land Mosaics: The Ecology of Landscapes and Regions. Cambridge University Press, Cambridge.

Gaston, K.J., Blackburn, T.M., 2000. Pattern and process in macroecology. Blackwell Science, Oxford.

Gisiger, T., 2001. Scale variance in biology: coincidence or footprint of a universal mechanism? Biol. Rev. 76, 161-209.

Harte, D., 2001. Multifractals: Theory and Applications. Chapman \& Hall/CRC, New York.

Harte, J., Kinzig, A., Green, J., 1999. Self-similarity in the distribution and abundance of species. Science 284, 334-336.

Hauhs, M., Kastner-Maresch, A., Rost-Siebert, K., 1995. A model relating forest growth to ecosystem-scale budgets of energy and nutrients. Ecol. Model. 1, 229-243.

Hentschel, H.G.R., Procaccia, I., 1983. The infinite number of generalized dimensions of fractals and strange attractors. Physica D 8, 435-444.

Kéfi, S., Rietkerk, M., Alados, C.L., Pueyo, Y., ElAich, A., Papanastasis, V., de Ruiter, P.C. 2007. Spatial vegetation patterns and imminent desertification in arid ecosystems. Nature 449, 213-218.

Kendal, W.S., 1992. Fractal scaling in the geographic distribution of populations. Ecol. Model. 64, 65-69.

Klomp, N.I., Green, D.G., 1996. Connectivity in landscapes and ecosystems. In: Stocker, R., Jelinek, H., Bossomaier, T. (Eds.), Complex systems-from local interactions to global behaviour. IOS Press, Amsterdam, pp. 46-56.

Kravchenko, A.N., Boast, C.W., Bullock, D.G., 2000. Multifractal analysis of soil spatial variability. Agron. J. 91, 1033-1041.

Levin, S.A., 1992. The problem of pattern and scale in ecology. Ecology 73, 1943-1967.

Loehle, C., Wein, G., 1994. Landscape habitat diversity-a multiscale information-theory approach. Ecol. Model. 73, 311-329.

Ma, K.M., Zu, Y.G., Godron, M., 2001. Scale correlation between vegetation and soil in larch forest, NE China. J. Environ. Sci. 13, 51-57.

Martinez, F.S., Caniego, J., Guber, A., Pachepsky, Y., Reyes, M., 2009. Multifractal modeling of soil microtopography with multiple transects data. Ecol. Complex. 6, 240-245.
Masek, J.G., Turcotte, D.L., 1993. A diffusion-limited aggregation model for the evolution of drainage networks. Earth Planet. Sci. Lett. 119, 379-386.

Maurer, B.A., Taper, M.L., 2002. Connecting geographical distributions with population processes. Ecol. Lett. 5, 223-231.

Milne, B.T., 1991. Lessons from applying fractal models to landscape patterns. In: Turner, M.G., Gardner, R.H. (Eds.), Quantitative Methods in Landscape Ecology. 82. Springer-Verlag, New York, pp. 199-239.

Milne, B.T., 1992. Spatial Aggregation and Neutral Models in Fractal Landscapes. Am. Nat. 139, 32-57.

Montero, E., 2005. Rényi dimensions analysis of soil particle-size distributions. Ecol. Model. 182, 305-315.

Nagendra, H., Southworth, J. (Eds.), 2010. Reforesting Landscapes: linking patterns and processes. Springer.

Ostling, A., Harte, J., Green, J.L., Kinzig, A.P., 2004. Self-similarity, the power law form of the species-area relationship, and a probability rule: a reply to Maddux. Am. Nat. 163, 627-633.

Padilla, F.M., Pugnaire, F.I., 2006. The role of nurse plant in the restoration of degraded environments. Front. Ecol. Environ. 4 (4), 196-202.

Pagnutti, C., Azzouz, M., Anand, M., 2007. Propagation of local interactions creates global gap structure and dynamics in a tropical rainforest. J. Theor. Biol. 247, 68-181.

Rényi, A., 1970. Probability theory. North-Holland, Amsterdam.

Ricotta, C., 2000. From theoretical ecology to statistical physics and back: self-simila landscape metrics as a synthesis of ecological diversity and geometrical complexity. Ecol. Model. 125, 245-253.

Ricotta, C., Anand, M., 2006. Spatial complexity of ecological communities: bridging the gap between probabilistic and non-probabilistic uncertainty measures. Ecol. Model. 197, 59-66.

Rudel, T.K., Coomes, O.T., Moran, E., Achard, F., Angelsen, A., Xu, J., Lambin, E., 2005. Towards a global understanding of land use change. Global Environ. Change A 15, 23-31.

Scanlon, T.M., Caylor, K.K., Levin, S.A., Rodriguez-Iturbe, I., 2007. Positive feedbacks promote power law clustering of Kalahari vegetation. Nature 449, 209-213.

Scheuring, I., Riedi, R.H., 1994. Application of multifractals to the analysis of vegetation pattern. J. Veg. Sci. 5, 489-496.

Sintes, T., Marbà, N., Duarte, C.M., Kendrick, G.A., 2005. Nonlinear processes in seagrass colonisation explained by simple clonal growth rules. Oikos 108, 165-175.

Song, C.H., Zhang, Y.X., 2010. Forest Cover in China from 1949 to 2006. In: Nagendra, H. Southworth, J. (Eds.), Reforesting Landscapes: Linking Pattern and Process. Springer, pp. 341-356.

Sturtevant, B.R., Gustafson, E.J., Li, W., He, H.S., 2004. Modeling biological disturbances in LANDIS: a module description and demonstration using spruce budworm. Ecol. Model. 180, 153-174.

Tang, Q., 2008. Scaling behaviour of diffusion limited aggregation in percolation cluster. Mod. Phys. Lett. B. 22, 507-513.

Turner, M.G., Romme, W.H., 1994. Landscape dynamics in crown fire ecosystems. Landscape Ecol. 9, 59-77.

Vicsek, T., 1992. Fractal Growth Phenomena. World Scientific, Singapore.

West, G.B., Brown, J.H., 2005. The origin of allometric scaling laws in biology from genomes to ecosystems: towards a quantitative unifying theory of biological structure and organization. J. Exp. Biol. 208, 1575-1592.

West, G.B., Enquist, B.J., Brown, J.H., 2009. A general quantitative theory of forest structure and dynamics. PNAS 106 (17), 7040-7045.

White, E.P., Enquist, B.J., Green, J.L., 2008. On estimating the exponent of power-law frequency distributions. Ecology 89, 905-912.

Wiens, J.A., 1989. Spatial Scaling in Ecology. Funct. Ecol. 3, 385-397.

Witten, T.A., Sander, L.M., 1981. Diffusion-Limited Aggregation, a Kinetic Critical Phenomenon. Phys. Rev. Lett. 47, 1400-1403.

Zeleke, T.B., Si, B.C., 2004. Scaling properties of topographic indices and crop yield: Multifractal and joint multifractal approaches. Agron. J. 96, 1082-1090.

Zhang, Y.X., Ma, K.M., Anand, M., Fu, B.J., 2006. Do generalized scaling laws exist for species abundance distribution in mountains? Oikos 115, 81-88. 